\title{
Word unitization examined using an interference paradigm
}

\author{
WILLIAM O'HARA and CHARLES W. ERIKSEN \\ University of Illinois at Urbana-Champaign, Champaign, Illinois 61820
}

\begin{abstract}
A "same"."different" interference paradigm was utilized to investigate the differential nature of word nonword processing. Eight subjects viewed tachistoscopically presented pairs of letters and made speeded comparison judgments on the basis of name identity. When present, noise trigrams composing words or anagrams were positioned directly between the target letters. The results supported a word unitization hypothesis of word recognition. Anagrams increased RTs for "same" responses more than their counterpart words when used as noise items. The data are interpreted in terms of selective attention, response competition, and models of word recognition.
\end{abstract}

Recently, Johnson $(1975,1977)$ has proposed a pattern-unit model of word recognition to account, at least in part, for the acquisition and performance of the component skills required in reading. In a similar but broader vein, Hayes-Roth (1977) developed the knowledge-assembly theory. Both researchers provide two suppositions that have bearing on the problem of written word recognition: (1) Words can be treated perceptually as individual units, and (2) individual letters contained within such words need not be recognized prior to the words' recognition.

Whole word theories of word recognition are not new. Cattell (1886) and Huey (1908/1968) had also hypothesized that it was the whole word, instead of individual letters, that constituted the unit of perception in reading. In support of this hypothesis, Huey reported that words having distinctive outlines were correctly identified at distances far too great to identify single letters, and Cattell showed that short words could be verbalized as quickly as single letters. More recently, support has come from evidence that words having common outlines are frequently mistaken for words having similar outlines (Havens \& Foote, 1963), and under certain conditions recognition accuracy for single letters is better when they are embedded in words than in nonwords or displayed alone (Reicher, 1969; Wheeler, 1970). Also, Johnson (1975) found that words can be identified more quickly than letters within words.

Although it seems quite evident from the above discussion that readers handle words differently from nonwords or single letters, it is not as evident that the whole word hypothesis is the best explanation of the process involved in word recognition. In fact, several researchers (Henderson, 1975; Sloboda, 1976) have argued that Johnson's $(1975,1977)$ results failed to offer substantial support for it. McClelland (1977) argues that a preliminary letter-based model incorporat-

This research was supported by Public Health Service Research Career Program Award K6-MH-22014 to the second author and by U.S. Public Health Service Research Grant MH-01206. ing a parallel letter analysis process could easily and more accurately explain such a process.

The focus of the present experiment was to provide fresh evidence on the whole word hypothesis. A response competition paradigm was used. Eriksen and Eriksen (1974) and Eriksen and Hoffman (1973) have shown that reaction time (RT) to a target letter is substantially increased if the target is flanked by noise letters that call for an incompatible response. Keren, O'Hara, and Skelton (1977) have extended this competition paradigm to same-different judgments. In one of their experiments, subjects were required to view tachistoscopically presented target letters and make speeded same-different responses on the basis of name identity. On some trials, two noise letters appeared, positioned between the target letters. When response-incompatible noise letters were positioned between physically identical target letters (e.g., A MM A), "same" RTs were impaired as compared to no-noise or noise-compatible conditions (e.g., A A and AaaA, respectively). Similar results were obtained when the target letters were name identical (e.g., A a). Keren et al. concluded that subjects were not able to attend selectively to the target letters, and that the presence of incompatible noise items resulted in response competition.

The present experiment was quite similar to that of Keren et al. (1977), but instead of using letter pairs as noise items, letter trigrams were used. These trigrams formed either common words or anagrams. In addition to having the three types of target letter pairs (physically identical, name identical, and different), there were three noise conditions (no-noise, word, and anagram). It was anticipated that if words are recognized as familiar units instead of individual sets of letters, word noise would not increase "same" RTs as greatly as anagram noise, since the unitized word would not be confused with the target letters. Anagrams, however, would be more apt to be processed as free-floating letters and thus produce interference effects similar to those reported by Keren et al. (1977). 


\section{METHOD}

\section{Subjects}

Eight University of Illinois students served as paid volunteers. Each was right-handed and had either normal or correctedto-normal vision.

\section{Stimuli and Apparatus}

Target stimuli consisted of black letters typed on white index cards using IBM Prestige Elite 12 type. At the viewing distance of $84 \mathrm{~cm}$, the letters subtended .14 and $.24 \mathrm{deg}$ of visual angle in width and height, respectively. Displays were composed of either two target letters alone (null condition) or two target letters and a capital letter trigram (word and anagram conditions). The target letters always appeared at the extreme right and left of the visual display, separated by $1.27 \mathrm{deg}$ of visual angle. When included in the display, the noise trigram, subtending $.437 \mathrm{deg}$ of visual angle, always appeared directly between the two target letters.

Physically identical (PI) letter pairs consisted of five uppercase and five lowercase letters chosen randomly from the alphabet with the restriction that none of the selected letters have physical features descending below the writing line (e.g., y or g). Name identical (NI) pairs were constructed by changing the case of one of the letters in each of the PI letter pairs. Five of the NI pairs began and five ended in uppercase letters.

Word trigrams were chosen from a group of 10 words randomly selected from a list provided by Kučera and Francis (1967). These words varied in frequency of usage from approximately $3 / 10^{6}$ for APE to approximately $1772 / 10^{6}$ for CAN. The 10 anagrams used in this experiment were produced by repositioning the second letter of each word to the first or third position so as to produce a nonword. The targets and noise stimuli are shown in Table 1.

"Different" letter pairs were constructed using the same letter set used for the "same" letter pairs. The pairs were made with the restrictions that 10 of the letter pairs were composed of same case letters (upper- or lowercase), 10 had mixed letter cases, and all the letters had to be used equally often.

The stimuli were displayed with a Scientific Prototype Model $800 \mathrm{~F}$ two-field tachistoscope equipped with ITT F6T5/ CW fluorescent lamps. Luminances of the white background for both fields were set at $24 \mathrm{c} / \mathrm{m}^{2}$. RTs were recorded to the nearest millisecond on a Hunter Klockounter.

\section{Procedure}

Subjects were told to fixate on a small cross that appeared in the center of the field and then to initiate a trial by pushing a button held in the left hand. Immediately thereafter, the fixation field was replaced by the stimulus display that remained on for $250 \mathrm{msec}$. After this period, the fixation field reappeared.

The subjects were instructed to move a lever to the left (right) with the right hand whenever the target letters were NI and to the right (left) when the targets had different names. Direction of response was counterbalanced over subjects. The subjects were also told that on some trials, words or anagrams would appear in the center of the experimental display, but these trigrams had nothing to do with the task and should be ignored.

Finally, the subjects were instructed to respond as rapidly as possible, but to attempt to maintain a low error rate. After each trial, both RT and accuracy feedback were provided for the subject. Trials on which errors were made were not rerun.

Each subject participated in only one experimental session. Before collecting data, subjects received practice, during which they made responses to 40 no-noise trials and 10 noise trials. Following this warm-up, each subject received 120 experimental trials, two random presentations of each of the 60 displays.
Table 1

Examples of the Target Letters and Noise Trigrams Used in the Experiment

\begin{tabular}{|c|c|c|c|c|c|}
\hline \multicolumn{2}{|c|}{ "Same" } & \multirow[b]{2}{*}{ Word } & \multirow[b]{2}{*}{$\begin{array}{l}\text { Non- } \\
\text { word }\end{array}$} & \multicolumn{2}{|c|}{ "Different" } \\
\hline $\begin{array}{l}\text { Physically } \\
\text { Identi- } \\
\text { cal }\end{array}$ & $\begin{array}{c}\text { Name } \\
\text { Identi- } \\
\text { cal }\end{array}$ & & & $\begin{array}{l}\text { Same } \\
\text { Case }\end{array}$ & $\begin{array}{l}\text { Differ- } \\
\text { ent } \\
\text { Case }\end{array}$ \\
\hline $\mathrm{m}_{--} \mathrm{m}$ & $\mathrm{M}_{--} \mathrm{m}$ & APE & PAE & $\mathrm{t} \ldots \mathrm{s}$ & $\mathrm{m}_{-} \_\mathrm{H}$ \\
\hline$d_{\ldots} d$ & $\mathrm{~d}_{--\mathrm{D}}$ & DOG & ODG & $s \rightarrow d$ & $A_{-\ldots} d$ \\
\hline$e_{-\ldots}$ & $\mathrm{E}_{-}-\mathrm{e}$ & HAT & HTA & $\mathrm{e} \ldots \ldots \mathrm{m}$ & e $\ldots B$ \\
\hline$t--t$ & $t--T$ & JOB & $\mathrm{JBO}$ & $\mathrm{d}_{--\mathrm{e}}$ & $R_{--} t$ \\
\hline$s--s$ & $S_{--} \mathrm{s}$ & KID & KDI & $m_{--t}$ & 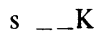 \\
\hline $\mathrm{H}_{-}-\mathrm{H}$ & $h_{--} \mathrm{H}$ & LIP & LPI & $\mathrm{H}_{-}-\mathrm{R}$ & $\mathrm{H}_{-}-\mathrm{s}$ \\
\hline$A_{-}-\mathbf{A}$ & $A_{--a}$ & MAN & AMN & $A_{--K}$ & $A_{-\ldots} t$ \\
\hline$B_{\ldots}$ B & $b_{-} B$ & PIN & IPN & $R_{--B}$ & e $\ldots$ B \\
\hline $\mathbf{R}_{-} \mathbf{R}$ & $R_{--r}$ & SOX & SXO & $\mathrm{B}_{--} \mathrm{A}$ & $d_{-}-R$ \\
\hline$K_{-}-\mathrm{K}$ & $k_{-}-\mathrm{K}$ & CAN & ANC & $\mathrm{K}_{-}-\mathrm{H}$ & $\mathrm{m}_{--} \mathrm{K}$ \\
\hline
\end{tabular}

\section{RESULTS}

\section{"Same" Results}

The results are illustrated in Figure 1, where "same" RTs averaged across subjects are plotted as a function of target type (PI or NI) and noise type (null, word, or anagram). A repeated-measures analysis of variance (target type by noise type) yielded significant main effects of target type $[\mathrm{F}(1,7)=27.27, \mathrm{p}<.01]$ and noise type $[F(2,14)=12.08, p<.01]$, with a significant interaction $[\mathrm{F}(2,14)=5.43, \mathrm{p}<.01]$. The significant effect of level of target match replicates previous findings (Keren et al., 1977; Posner \& Mitchell, 1967) and reflects the fact that subjects are more rapid in determining that two letters are NI when they are actually PI as well.

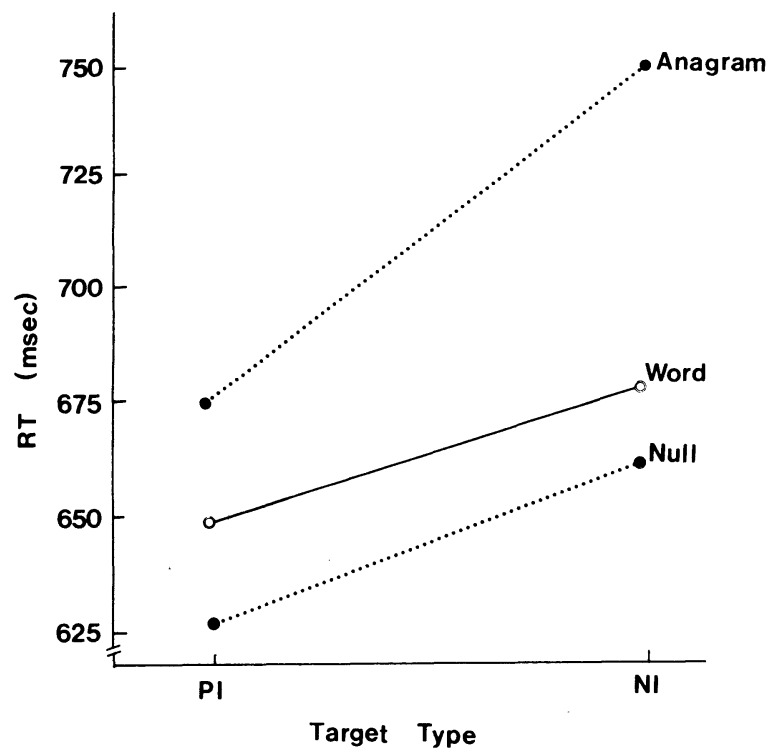

Figure 1. Mean RTs for correct "same" judgments as a function of target type (physically identical, PI, or name identical, NI) and noise type (no-noise, word, and anagram). 
The more important findings, however, relate to the effects of noise type. Noise trigrams significantly increased RTs to both PI and NI target letters. The significance of this effect is due to anagram, not word noise. A separate repeated-measures analysis of variance comparing the no-noise, word-noise, and the targettype conditions revealed a significant main effect of target type $[F(1,7)=7.75, p<.05]$, but no significant noise-type or interaction effect $(p>.05)$. On the other hand, when the null noise conditions were excluded from the analysis and a repeated-measures analysis of variance was computed comparing the anagram and word noise, significant main effects were found both for target type $[F(1,7)=39.84, p<.01]$ and noise type $[F(1,7)=36.85, p<.01]$, as well as a significant interaction $[F(1,7)=14.4, p<.01]$. Thus, it appears that when present, word noise interfered very slightly, if at all, with the subjects' ability to respond to the letter targets.

The effects of anagram-noise elements, however, were quite different. When an anagram was included between the two target letters, mean RT increased $44 \mathrm{msec}$ for the PI target match and $86 \mathrm{msec}$ for the NI target match.

Examination of error rates gave no indication of any speed-accuracy tradeoffs, since the error rates generally increased with RTs across conditions. Error rates were $6.87 \%$ for PI matches and $11.25 \%$ for NI matches when the data were collapsed across the different noise conditions. For the noise conditions collapsed across the levels of target match, the error rates were $7.19 \%$, $9.38 \%$, and $10.63 \%$ for the no-noise, word-noise, and anagram-noise conditions, respectively.

\section{"Different" Results}

Again, a repeated-measures analysis of variance (target type by noise type) was used to analyze "different" RTs. The analysis revealed no significant main effects or interaction $(p>.05)$. Considering previous findings, this was anticipated. Beller (1970) and Keren et al. (1977) found that when the noise items were dissimilar to the target items, "different" responses were facilitated and "same" responses were inhibited. In the present study, the individual letters in the anagrams were different from the target letters, and when the targets were dissimilar, no response competition occurred. Both the dissimilar target and the different noise letters tended to activate "different" judgments.

As with the "same" results, examination of error data revealed no indication of any speed-accuracy tradeoffs.

Finally, the mean RT for "same" responses (686.8) was faster than the average RT for "different" responses (698.7). This result is in agreement with the data found in most same-different experiments (cf. Krueger, 1978; Nickerson, 1972).

\section{DISCUSSION}

The results of this experiment yield two main conclusions: (1) Subjects are not able to selectively attend solely to the specified targets and ignore irrelevant stimuli in the visual field, and (2) three-letter words are perceived quite differently than anagrams of the same letters when these stimuli are used as the irrelevant noise.

The first conclusion has been amply demonstrated before, not only with the Stroop effect (see Dyer, 1973, for review), but also on tasks requiring letter identification (Eriksen \& Eriksen, 1974; Eriksen \& Hoffman, 1973), and same-cifferent judgments (Keren et al., 1977; Krueger, 1973). This nonselective nature of selective attention underlies the response competition effect and renders the paradigm useful in studying various aspects of visual information processing (Eriksen \& Schultz, 1979).

The second conclusion supports the hypothesis of word unitization. It is important to note that the words and anagrams were composed of the same letters (see Table 1). Therefore, the difference in RT performance between the two conditions must be attributable to a selective interference difference between the two noise types, indicating that words are unitized as proposed by Hayes-Roth (1977) and Johnson (1975, 1977). If so, a word's featural or memorial representation may be in fact a neutral irrelevant stimulus, when the nature of the comparison task is considered. That is, as Johnson (1977) pointed out, the features comprising the perceptual unit for a word need have little relation to those of any of the word's constituent letters. Given that a word is unitized, its new representation or cognitive assembly (Hayes-Roth, 1977) need not be confusable with individual target letters, and would therefore not be expected to produce response competition and elevate RTs for "same" or "different" judgments. Anagrams, however, not being representative of anything other than their own individual letters, are likely to be processed as groups of free-floating letters that become prime candidates for target noise-confusable items. They therefore produce response competition and the observed increase in "same" RTs.

The interaction of anagram noise and level of target match can be explained by using the concepts of response competition as discussed by Eriksen and associates and levels of processing (Craik \& Lockhart, 1972; Keren et al., 1977). Accordingly, it would be predicted that anagram noise would increase "same" RTs to NI stimuli more than to PI stimuli. A PI "same" match may be accomplished at the featural level. There is no need to determine the names of the individual targets. Any interference or response competition would therefore be expected at the featural level alone. When the level of target match is at the name level, something different is expected. The subject is forced to process the target letters to the level of a name match before a response can be made (Posner \& Mitchell, 1967). Besides being at a higher cognitive level of processing than a physical match, the letter-naming process causes names to be determined for the noise letters also (Keren et al., 1977). This results in maximum response competition. Not only do the target and noise items differ on the featural level, but also on the name level.

Finally, apart from the basic theoretical issues examined by this experiment, there is another point of interest, namely, the demonstration of the paradigmatic value of a same-different design coupled with the use of noise items. As noted, this design was utilized in the present experiment to provide fresh evidence for word unitization. Elsewhere, it has been used to furnish data concerning selective attention, levels of processing (Keren et al., 1977), and basic comparison processes (Krueger, 1970, 1973). 


\section{REFERENCES}

Beller, H. K. Parallel and serial stages in matching. Journal of Experimental Psychology, 1970, 84, 213-219.

Cattell, J. The time taken up by cerebral operations. Mind, $1886,11,220-242$.

Craik, F. I. M., \& LockharT, R. S. Levels of processing: A framework for memory research. Journal of Verbal Learning and Verbal Behavior, 1972, 11, 671-684.

DYER, F. N. The Stroop phenomenon and its use in the study of perceptual, cognitive, and response processes. Memory \& Cognition, 1973, 1, 106-120.

Eriksen, B. A., \& Eriksen, C. W. Effects of noise letters upon the identification of a target letter in a nonsearch task. Perception \& Psychophysics, 1974, 16, 143-149.

Eriksen, C. W., \& Hoffman, J. E. The extent of processing of noise elements during selective encoding from visual displays. Perception \& Psychophysics, 1973, 14, 155-160.

Eriksen, C. W., \& Schultz, D. W. Information processing in visual search: A continuous flow conception and experimental results. Perception \& Psychophysics, 1979, 25, 249-263.

Havens, L. L. \& Foote, W. E. The effect of competition on visual duration threshold and its independence of stimulus frequency. Journal of Experimental Psychology, 1963, 65, 6-11.

HAYES-ROTH, B. Evolution of cognitive structures and processes. Psychological Review, 1977, 84, 260-278.

Henderson, L. Do words conceal their component letters? A critique of Johnson (1975) on the visual perception of words. Journal of Verbal Learning and Verbal Behavior, 1975, 14, 648-650.

Huey, E. B. The psychology and pedagogy of reading. Cambridge, Mass: MIT Press, 1968. (Originally published 1908.)

Johnson, N. F. On the function of letters in word identification: Some data and a preliminary model. Journal of Verbal Learning and Verbal Behavior, 1975, 14, 17-29.

Johnson, N. F. A pattern unit model of word identification.
In D. LaBerge \& S. J. Samuels (Eds.) Basic process in reading: Perception and comprehension. New York: Erlbaum, 1977.

Keren, G., O'Hara, W. P., \& Skelton, J. M. Levels of noise processing and attentional control. Journal of Experimental Psychology: Human Perception and Performance, 1977, 3, 653664.

KRUEGER, L. E. Effect of bracketing lines on speed of "same""different" judgment of two adjacent letters. Journal of Experimental Psychology, 1970, 84, 324-330.

Krueger, L. E. Effects of irrelevant surrounding material on the speed of same-different judgments of two adjacent letters. Journal of Experimental Psychology, 1973, 98, 252-259.

Krueger, L. E. A theory of perceptual matching. Psychological Review, 1978, 85, 278-304.

Kučera, H., \& Francis, W. N. Computational analysis of present day American English. Providence, RI: Brown University Press, 1967.

McClelland, J. L. Letter and configuration information in word identification. Journal of Verbal Learning and Verbal Behavior, 1977, 16, 137-150.

Nickerson, R. S. Binary-classification reaction time: A review of some studies of human information-processing capabilities. Psychonomic Monograph Supplements, 1972, 4, 275-318.

Posner, M. I., \& Mitchell, R. F. Chronometric analysis of classification. Psychological Review, 1967, 74, 392-409.

Reicher, G. M. Perceptual recognition as a function of meaningfulness of stimulus material. Journal of Experimental Psychology, 1969, 81, 274-280.

Sloboda, J. A. Decision times for word and letter search: A holistic word identification model examined. Journal of Verbal Learning and Verbal Behavior, 1976, 15, 93-101.

Wheeler, D. D. Processes in word recognition. Cognitive Psychology, 1970, 1, 59-85.

Received for publication May 3, 1979. 